\title{
Experimental Study on Characteristics of Rock Material under Thermal Mechanical Coupling
}

\author{
Xiao-Feng MA \\ School of Equipment and Engineering, University of CPFA, Xi'an 710086, China \\ 943870101@qq.com \\ ${ }^{*}$ Corresponding author
}

Keywords: Characteristics, Rock Material, Thermal Mechanical, Coupling.

\begin{abstract}
This paper aims to the physical characteristics of rock mass in the course of rising from room temperature to $600^{\circ} \mathrm{C}$. The maximum stress is reduced from $29.95 \mathrm{MPa}$ to $15.65 \mathrm{MPa}$ when the temperature rises above 400 degrees, the modulus of elasticity decreased by even more than $90 \%$ between 250 and $400^{\circ} \mathrm{C}$. The rock Poisson ratio is gradually increasing when the temperature rises from 30 to $100^{\circ} \mathrm{C}$, the Poisson's ratio decreases sharply with the temperature rising from 100 to $300^{\circ} \mathrm{C}$.
\end{abstract}

\section{Introduction}

The rock layer will have a larger strain and there are cracks in the local area when the temperature reaches $600-700^{\circ} \mathrm{C}$. The increase of temperature gradient will lead to the increase of thermal stress due to temperature rise. Thermal stress can also cause the destruction of rock mass, which will causes the crack width and length to be changed further ${ }^{[1,2]}$. The re-distribution of the stress changes the permeability of rock mass, so that the flow characteristics of the gas can be changed ${ }^{[3,4]}$.

\section{Experimental Principle}

Due to different internal and external environment, the temperature will be different. The stress influence will change the physical structure of the rock mass; when the temperature difference is large the expansion between particles is not uniform in mutual constraints which will produce thermal stress. When the temperature increases, the relationship between the thermal stress and the temperature is defined as

$$
\sigma_{h}=\left(T_{e}-T_{s}\right) K \cdot E \cdot A
$$

Where, $\sigma_{h}$ is thermal stress. $E$ stands for elastic modulus of rock mass, Pa; $A$ is linear expansion coefficient; $K$ is heat transfer coefficient, $\mathrm{W} /(\mathrm{m} \cdot \mathrm{K}) ; T_{\mathrm{s}}$ is initial temperature, ${ }^{\circ} \mathrm{C} ; T_{\mathrm{e}}$ is measured temperature, ${ }^{\circ} \mathrm{C}$.

Eq. 1 shows that elastic modulus, linear expansion coefficient and thermal conductivity are related to temperature and thermal stress. Thermal conductivity is not easy to form a larger stress, which leads to the difference of the mechanical properties of rock mass. The parameters of thermal physical properties of rock mass are mainly: thermal conductivity, specific heat, thermal conductivity, heat exchange coefficient and so on.

\section{Experimental Methods}

The equipment used 815.02 electric hydraulic three axis rock mechanics experiment system. The control system is independent of closed loop control; it can monitor the test process in real time and can complete the data of multiple channels simultaneously ${ }^{[5]}$. The axial pressure, confining pressure and pore water pressure can be controlled separately, and the maximum confining pressure can reach up to $80 \mathrm{MPa}$, and the axial load is up to $4600 \mathrm{kN}$. 
Tab.1 Parameters of Mechanics Test System

\begin{tabular}{clcl}
\hline specifications & parameters & Specifications & parameters \\
\hline axial & $\leq 4600 \mathrm{KN}$ & $\begin{array}{c}\text { Servo valve } \\
\text { sensitivity }\end{array}$ & $290 \mathrm{~Hz}$ \\
$\begin{array}{c}\text { compression } \\
\text { Water osmotic } \\
\text { pressure } \\
\text { difference }\end{array}$ & $\leq 2 \mathrm{MPa}$ & $\begin{array}{c}\text { Maximum height } \\
\text { of specimen }\end{array}$ & $190 \mathrm{~mm}$ \\
\hline
\end{tabular}

The experimental samples obtained by the drilling machine of rock drilling mainly consist of quartz, calcite and siderite, and make the rock specimen drying in the dry dish spare.

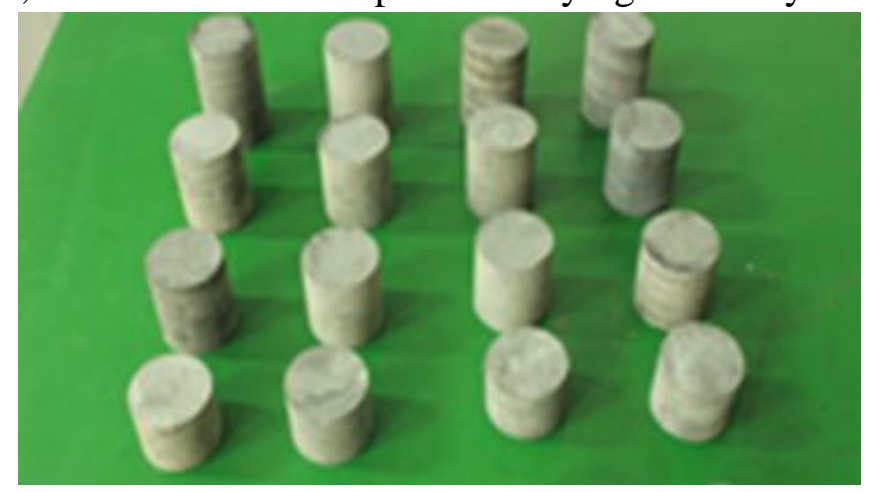

Fig.1 Standard Test Piece of Rock Mass

Select 16 samples from the rock specimen and heat the sample, each were divided into 4 groups through the experimental control system; the heating rate is $5^{\circ} \mathrm{C} / \mathrm{min}$. In order to make the test piece evenly heated, when the temperature rises to $100^{\circ} \mathrm{C}, 200,300,400,500,600^{\circ} \mathrm{C}$ keep the constant temperature for $45 \mathrm{~min}$.

Before the experiment, load tri-axial pressure chamber, tight the axial fixation in accordance with the experimental rules, try the pressure head fixed, tight the screws, connect the liquid at the lower end, and fasten the heat shrinkable tube ends by the wire. Confine initial axial pressure, confining pressure, inlet pressure on the test piece to a predetermined value; the axial pressure is applied firstly and boosts to preset value at $0.002 \mathrm{~mm} / \mathrm{s}$ displacement rate and $0.02 \mathrm{MPa} / \mathrm{s}$ pressure rate until the specimen of rock damaged. The system automatically records the whole process, completes the test piece displacement, the stress and the strain and the other parameters ${ }^{[6]}$.

\section{Physical Characteristics Analysis}

\section{Peak Stress and Peak Strain of Rock Specimen}

It can be seen from Fig.2 that the rock peak stress is gentle at the beginning variation with the temperature changing, when the temperature higher than $300^{\circ} \mathrm{C}$, the stress significantly increased and the peak stress occurs. When the temperature exceeds $400^{\circ} \mathrm{C}$, the physical properties changes, peak stress decreased obviously. The Peak stress maximum value varies from $29.95 \mathrm{MPa}$ to $15.65 \mathrm{MPa}$, a decline of nearly half. It can be conclude that the weakening effect of high temperature on the strength of the specimen is obvious, that is mainly due to the interior crystal heated which caused the generation of new crack. In order to study the influence of peak stress and peak strain on the geological process. Average and fit the 4 group of the experiment data the result is shown in Fig.2, and the correlation coefficient is 0.81 . 


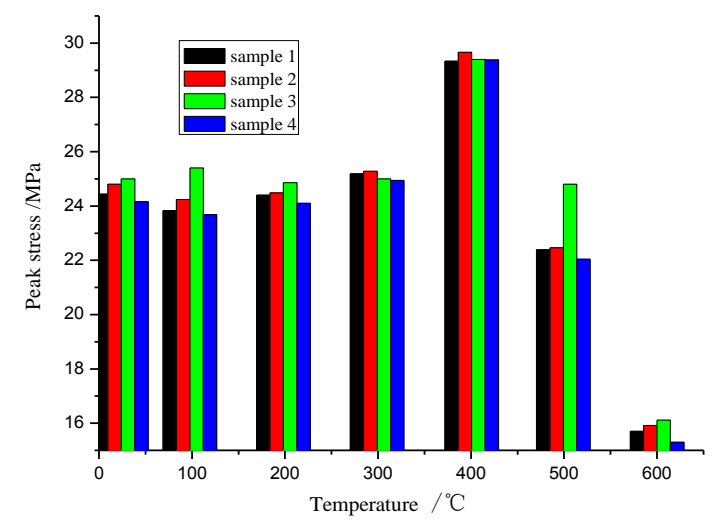

Fig.2 The Rock Peak Diagram between Stress and Temperature

The fitting formula of rock peak and temperature as Equation (2).

$$
y=22.30+0.12 x-0.0017 x^{2}
$$

It can be seen from Fig. 3 that the rock peak strain sustained increase with the temperature continue to rise. Peak strain of some samples has small amplitude oscillations at about $300^{\circ} \mathrm{C}$; the peak strain increases more than $57 \%$ when the temperature exceeds $400^{\circ} \mathrm{C}$. When the temperature exceeds $600^{\circ} \mathrm{C}$, the increase of the peak strain keeps a stable level. From this it can be known that the peak strain showed different changes with the increase of temperature. High temperature reduces the internal structure stress and produce crack which weaken the ability of rock deformation resistant. After fitting and averaging the 4 groups of experimental data, the relationship between the rock peak strain and temperature is shown as Equation (3). The correlation coefficient is 0.96.

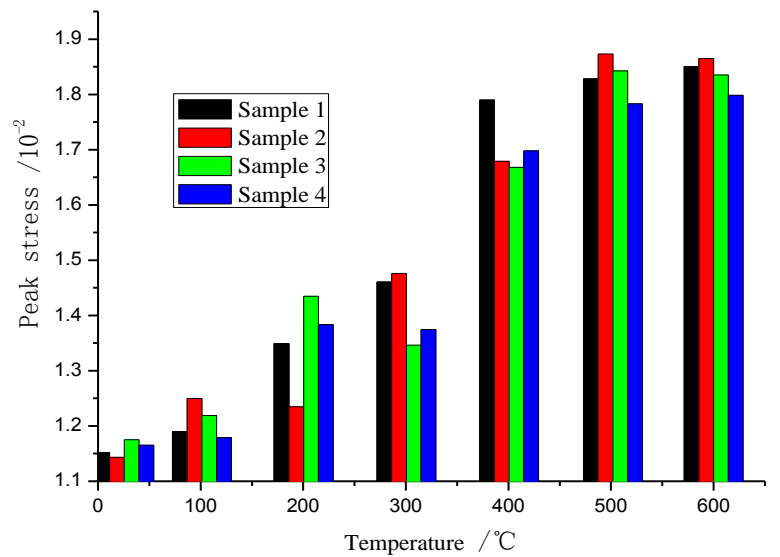

Fig.3 The Relation between Peak Strain And Temperature

$$
y=A_{1}+\left(A_{2}-A_{1}\right) /\left(1+10^{\wedge}\left(\left(\log x_{0}-x\right) \times p\right)\right)=1.16+0.72 /\left(1+10^{0.0053(323.77-x)}\right) .
$$

\section{Elastic Modulus and Deformation Modulus of Rock}

Rock elastic modulus and deformation modulus as shown in Figure 4 and figure 5, from which it can be seen that both are change small with the increase of temperature, and the variation range is larger. From temperature rising from 30 to $600^{\circ} \mathrm{C}$, the average decline of the elastic modulus about the 4 rock samples up to $15 \%$ the modulus of deformation is also decreased by more than $45 \%$. Due to the high temperature, the specimen minerals changes, thermal expansion coefficient are different and the internally heat stress generated. 


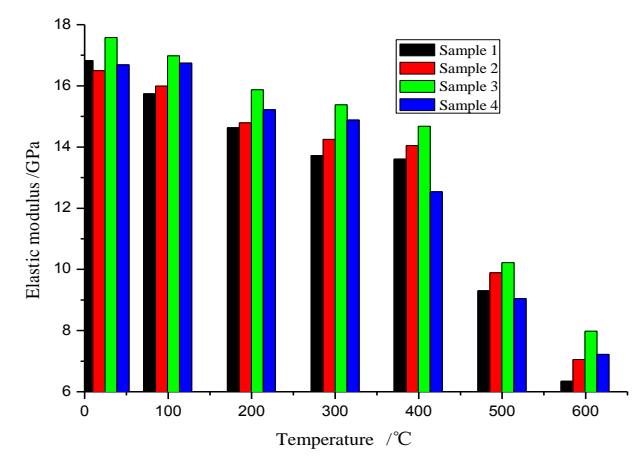

Fig.4 Relationship between the Elastic Modulus and the Temperature

The fitting formula of elastic modulus and temperature of samples as shown in Equation (4), the fitting correlation coefficient is 0.96 .

$$
y=A+B x+C x^{2}=16.55+0.0023 x-3.01 \times 10^{-5} x^{2}
$$

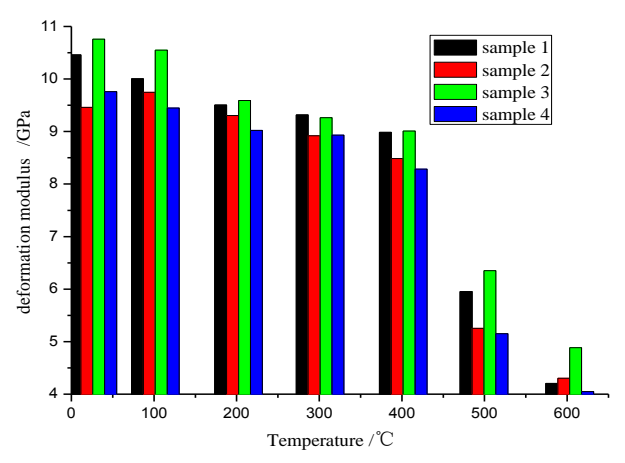

Fig.5 Relationship between Deformation Modulus and Temperature

The fitting formula of rock deformation modulus and the average temperature as shown in (5), the fitting correlation coefficient is 0.93 .

$$
y=A+B x+C x^{2}=9.85+0.004 x-2.2 \times 10^{-5} x^{2}
$$

\section{Poisson's Ratio of Rock Samples}

It can be found from Fig.6, when the temperature rises from 30 to $100^{\circ} \mathrm{C}$, the rock Poisson ratio is gradually increasing; when the temperature rises from 100 to $300^{\circ} \mathrm{C}$, the Poisson's ratio shows a sharp decline. From the beginning of 300 until $600^{\circ} \mathrm{C}$ the Poisson's ratio of the samples tends to be stable.

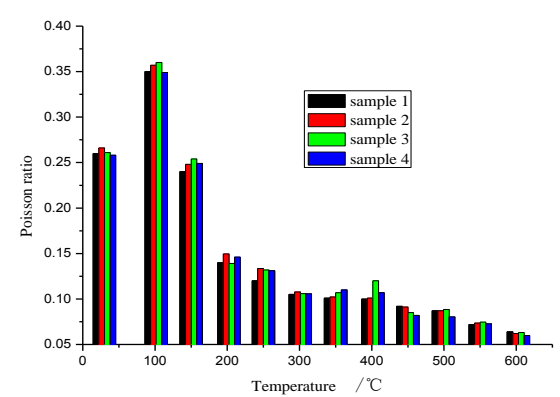

Fig.6 Poisson Ratio Curve with Temperature

The fitting relationship of the Poisson's ratio and temperature the following equation can be obtained; the fitting correlation coefficient is 0.896

$$
y=A_{2}+\left(\mathrm{A}_{1}-\mathrm{A}_{2}\right) /\left(1+\left(\mathrm{X} / \mathrm{X}_{0}\right)^{\mathrm{p}}\right)=0.089+0.218 /\left(1+(\mathrm{x} / 178.07)^{6.49}\right) .
$$




\section{Summary}

Through the physical characteristics of rock mass in the course of rising from room temperature to $600^{\circ} \mathrm{C}$ the test piece experienced the compaction stage, the elastic plastic stage and the shear failure stage with the temperature changes and the pressure difference. From the experimental results, the following conclusions are drawn.

(1) When the temperature rises above $400^{\circ} \mathrm{C}$, the maximum stress is reduced from $29.95 \mathrm{MPa}$ to 15.65MPa, Between 250 and $400^{\circ} \mathrm{C}$, the modulus of elasticity decreased by even more than $90 \%$.

(2) With the temperature rising from 30 to $100^{\circ} \mathrm{C}$, the rock Poisson ratio is gradually increasing; it decreases sharply with the temperature rising from 100 to $300^{\circ} \mathrm{C}$.

\section{References}

[1] Carman P C: Flow of Gases through Porous Media. Butterworth Publications, London, (1956).

[2] J. Denis N. Pone, Kim A.A. Hein, Glenn B. Stracher, et al. The spontaneous combustion of coal and its by-products in the Witbank and Sasolburg coalfields of South Africa [J]. International Journal of Coal Geology 72 (2007) 124-140.

[3] E.L. Heffern, D.A. Coates. Geologic history of natural coal-bed fires, Powder River basin, USA [J]. International Journal of Coal Geology 59 (2004) 25-47.

[4] McNabb A., Please C.P., McElwain D L S. Spontaneous combustion in coal pillars: Buoyancy and oxygen starvation. Mathematical Engineering in Industry. 1999, 7(3): 283-300.

[5] Stephansson O, Jing L, Tsang C F, et al. Coupled Thermo hydro-Mechanical Processes of Fractured Media [M]. Rotterdam Elsevier, 1996.

[6] Continillo G., Galiero G., Maffettone P. L., \& Crescitelli, S. Characterisation of the chaotic dynamics in the spontaneous combustion of coal stockpiles. Twenty Sixth symposium (international) on combustion. Pittsburgh: The Combustion Institute. 1996, 1585-1592. 